\title{
Evaluating the average access to care and continuity of care patients in Tehran teaching hospitals
}

\author{
Fereshteh Farzianpour ${ }^{1^{*}}$, Searajadein Gray $^{1}$, Abbas Rahimi Foroushani $^{2^{*}}$, \\ Mohammad Arab ${ }^{1}$, Shadi Hosseini ${ }^{3}$ \\ ${ }^{1}$ Department of Health Management and Economic, School of Public Health, Tehran University of Medical Sciences, Tehran, Iran; \\ *Corresponding Author: rahimifo@tums.ac.ir, farzianp@sina.tums.ac.ir \\ ${ }^{2}$ Department of Epidemiology and Biostatistics, School of Public Health, Tehran University of Medical Sciences, Tehran, Iran; \\ *Corresponding Author: farzianp2@yahoo.com \\ ${ }^{3}$ Department of Management, Management Faculty, Tehran University, Tehran, Iran
}

Received 25 October 2013; revised 26 November 2013; accepted 12 December 2013

Copyright (C) 2013 Fereshteh Farzianpour et al. This is an open access article distributed under the Creative Commons Attribution License, which permits unrestricted use, distribution, and reproduction in any medium, provided the original work is properly cited.

\section{ABSTRACT}

Background: Standards of Joint Commission International emphasize on the organizational performance level in basic functional domains including patient right, patient care, medical safety and infection control. These standards are focused on two principles: expectations of the actual organizational performance and assessment of organizational capabilities to provide high quality and safe health care services. The aim of this study is to evaluate the possibility of improvement in Access to Care and Continuity of Care for patients (ACC) in teaching hospitals of Tehran University of Medical Sciences. Methods: This cross-sectional study was conducted in hospitals affiliated to Tehran University of Medical Sciences during 2012. Data collection was performed using author-designed questionnaire of "Access to Care and Continuity of Care patients" based on JCl standards (2013). A total of 171 questionnaires were sent to 26 hospitals and 154 (90\%) questionnaires were successfully completed and used for data analysis. The questionnaire was reviewed by experts and the Cronbach's alpha was calculated to be 0.967 . The effects of the two variables of hospital type (general, specialty) and the number of beds on mean scores of ACC standards and each of its domains were analyzed using T-test or MannWhitney test depending on the distribution due to Kolmogorov-Smirnov test result. Results: In general, the mean of ACC standards was found comprehendible and applicable by $82.3(\mathrm{SD}=11)$ of the respondents. The highest and lowest mean scores of ACC questions belonged to hospitals H21 $(90 \pm 6)$ and H14 (67 \pm 12$)$, respectively. There were not any significant effects of hospital type and the number of beds on the ACC scores. Conclusion: There was not any important effect of hospital type and bed numbers on ACC, although there was a $9 \%-15 \%$ possibility of improvement in accreditation scores of ACC standards in hospitals of Tehran University of Medical Sciences. A complete accreditation score in this domain didn't seem achievable in these hospitals. However, it is proposed that future managerial planning of the studied hospitals lead to a complete accreditation score.

Keywords: Accreditation; Access to Care and Continuity of Care Patients; Joint Commission International; Hospitals of Tehran University of Medical Sciences

\section{INTRODUCTION}

Assessment of health care services is based on collecting valid and reliable data, which itself depends on choosing appropriate measurement techniques [1,2]. Global experience shows that using standards in providing the services can lead to promotion, efficiency and improved quality; while large organizations need to improve patient care quality and ensure safe care environment and continuous activity to reduce patient and staff risks in order to increase their share in care delivering markets and decrease their costs [3-5].

Meanwhile, standards of Joint Commission International (JCI) indicate the organizational performance level in key functional domains such as patient rights, patient 
care, medical safety and infection control. These standards are focused on two principles: expectations of the actual organizational performance and assessment of organizational capabilities to provide high quality and safe health care services [1-5]. Moreover, when it comes to attracting medical tourists, JCI standards are among the requirements of many insurance companies and people worldwide [6-11]. As McCallum and Jacoby have introduced having JCI accreditation as one of the main factors to determine the priority of health care providers in different countries [12], standards of Access to Care and Continuity of Care patients (ACC) are a part of health care organization management standards of JCI. These standards are considered as desirable and achievable standards and are designed to encourage ongoing corrective actions and proceedings [1-5].

In the previous studies carried out in selected hospitals of Tehran, Iran and Isfahan Medical Universities, mean adherence to ACC standards has been reported $69.7 \%$, $66 \%$ and $75 \%$, respectively [13-15]. JCI standards are easily available and can be used in public international areas by health care centers and public organizations of care quality improvement [2,3]. The question is that whether hospitals in Iran can get a complete score form JCI standards? And what are the causes of achieving complete or partial scores?

The aim of the present study is to evaluate the applicability of ACC standards in teaching hospitals of Tehran University of Medical Sciences and identify the causes of the difference between the achieved scores in this study with other studies.

\section{METHOD AND MATERIAL}

\section{Questionnaire Part}

This cross-sectional study was conducted in hospitals affiliated to Tehran University of Medical Sciences during 2012. Data collection was performed using authordesigned questionnaire of "availability and continuous care" based on JCI standards (2010); which included demographic data and 108 questions. The questionnaire covered 5 domains including "patient admission" with 36 questions, "care monitoring" with 11 questions, "discharge, referral and follow-up" with 27 questions, "patients transfer" with 21 questions and "patient transportation" with 13 questions. Each question had three choices with ranks of 3 = implementation, 2 = relatively implementation, 1 = non-implementation) and the total score of ACC and of each dimension of ACC was calculated by adding the ranks. The questionnaire was reviewed by experts and the total Cronbach's alpha was calculated 0.967 . Also to evaluate the reliability of each question of ACC, a Cronbach's alpha was calculated after removing the interested question from the set of all questions. Re- sults showed that these values were ranged from 0.851 to 0.864 . Each question was designed with three answers of yes (3 scores), partly (2 scores) and no (1 score). People asked to complete the questionnaire in each hospital in the priority order included hospital manager, clinical governance authorities, members of safety and accreditation committee and heads of the departments. The number of completed questionnaires differed from hospital to hospital due to weight of each hospital in number of beds, i.e. a proportional stratified simple random sampling was used to select the respondents. Moreover, hospitals websites were reviewed to obtain more information on issues related to accreditation and quality improvement. Since the main aim of the study was first to estimate the average of ACC scores in all hospitals, study sample size was determined based on 95\% confidence interval for the population mean of ACC so that no more than 3 scores error be existed in the estimation of the mean scores in each domain of the questionnaire. In total 171 questionnaires were sent to 26 hospitals and a total of 154 (90\%) questionnaires were successfully completed without any missing values and used for data analysis.

First, mean scores for each domain and a total score of ACC standards were calculated with respect to hospital characteristics and their normal distribution was investigated using Kolmogorov-Smirnov test (K-S test). Then the effect of the two variables of hospital type (general, specialty) and the number of beds on mean scores of ACC standards and each of its domains were analyzed using T-test or Mann-Whitney test depending on the distribution due to K-S test result. Statistical significance was set at 5\% and SPSS software version 20 was used for data analysis. Concurrent with questionnaire completion phase, some observational data was collected about type and methods of quality improvement and accreditation in hospitals as well as the ongoing processes and other related areas. Findings of this part are summarized as a SWOTs table.

\section{RESULTS}

Of the total 154 questionnaires, $45.5 \%$ were completed in general hospitals (110 to 659 beds, mean number: $399.6 \pm 151.7)$ and $54.5 \%$ were completed in specialty hospitals (109 to 451 beds, mean number: $209 \pm 126.8$ ). $58.2 \%$ of the respondents answered the question "are the ACC standards comprehensible and measurable in your hospitals?” with yes, 30.9\% answered partly and 10.7\% answered no. Regarding the domains, highest rate of yes answers was associated with "discharge, referral and follow-up domain" (65.1\%) and the lowest rate of yes answers belonged to "admission domain" (5.11\%). The range of answering with "partly" option ranged from $24.6 \%$ to $37.3 \%$ in different domains and mean rate of this answer was $30.9 \%$ for overall ACC standards. 
Choosing the "no" option ranged from $9.6 \%$ to $15 \%$ in different domains and mean frequency of it for overall ACC standards was $10.7 \%$ (Table 1). Highest and lowest scores belonged to "discharge, referral and follow-up domain” and "admission domain” (85.3 \pm 12 vs. $78.6 \pm$ 12 , respectively. ACC standards were considered comprehendible and measurable in average of $82.3 \pm 11$ by the respondents (Table 1).

Highest and lowest mean scores of ACC questions belonged to hospital H21 (90 \pm 6) and hospital H14 (67 \pm 12), respectively (Table 2 ).

Although there is a wide difference between the mean scores of the studied hospitals, according to post-Hoc test, only the difference between hospitals H5 and H18 is statistically significant $(\mathrm{P}$ value $=0.01)($ Figure 1$)$.

No significant difference was found between general and specialty hospitals regarding ACC standards and its domains $(\mathrm{P}$ value $=0.7)$. In addition, comparing the mean scores of the domains and total ACC score between hospitals with lower or higher than 300 beds showed no significant difference $(\mathrm{P}$ value $=0.7)($ Table 3$)$.

\section{Observational Findings}

Strength points: having experienced staff, educated in health care management field, with university degrees higher than bachelor, having clinical governance office, safety committee, accreditation committee, appropriate organizational environment for quality improvement and adherence to medical record standards.

Opportunities: supporting clinical governance offices by medical universities and ministry of health and medical education.

Weak points: using several accreditation and quality

Table 1. Percent, frequency and mean scores of the responses regarding the comprehensibility and measurability of the ACC standards and their domains.

\begin{tabular}{|c|c|c|c|c|c|}
\hline $\begin{array}{l}\text { Standard } \\
\text { domain }\end{array}$ & & Yes & Partly & No & Mean \pm SD \\
\hline \multirow{2}{*}{ Admission } & Percent & $51.1 \%$ & $33.8 \%$ & $15 \%$ & $78.6 \pm 12$ \\
\hline & Frequency & 87.6 & 52.3 & 23.1 & \\
\hline \multirow{2}{*}{$\begin{array}{c}\text { Continuous } \\
\text { care }\end{array}$} & Percent & $58.4 \%$ & $31.7 \%$ & $9.7 \%$ & $83 \pm 14$ \\
\hline & Frequency & 90 & 48.9 & 15 & \\
\hline \multirow{2}{*}{$\begin{array}{l}\text { Discharge, } \\
\text { referral and } \\
\text { follow-up }\end{array}$} & Percent & $65.1 \%$ & $24.6 \%$ & $9.7 \%$ & $85.3 \pm 12$ \\
\hline & Frequency & 101 & 38 & 15 & \\
\hline \multirow{2}{*}{$\begin{array}{l}\text { Patient } \\
\text { transfer }\end{array}$} & Percent & $62.8 \%$ & $27.4 \%$ & $9.6 \%$ & $85 \pm 14$ \\
\hline & Frequency & 96.7 & 42.2 & 14.8 & \\
\hline \multirow{2}{*}{$\begin{array}{c}\text { Patient } \\
\text { transportation }\end{array}$} & Percent & $53.9 \%$ & $37.3 \%$ & $9.8 \%$ & $81.6 \pm 14$ \\
\hline & Frequency & 81.3 & 56.9 & 15.1 & \\
\hline \multirow{2}{*}{$\mathrm{ACC}$} & Percent & $58.2 \%$ & $30.9 \%$ & $10.7 \%$ & $82.3 \pm 11$ \\
\hline & Frequency & 89.5 & 47.7 & 16.6 & \\
\hline
\end{tabular}

Table 2. Mean scores of ACC questions in the hospitals of Tehran University of Medical Sciences.

\begin{tabular}{|c|c|c|c|c|c|c|c|}
\hline Hospital & Mean \pm SD & Hospital & Mean \pm SD & Hospital & Mean \pm SD & Hospital & Mean \pm SD \\
\hline H1 & $82 \pm 12$ & H7 & $86 \pm 3$ & H13 & $67 \pm 14$ & H19 & $82 \pm 7$ \\
\hline H2 & $86 \pm 10$ & H8 & $87 \pm 7$ & H14 & $67 \pm 12$ & H20 & $84 \pm 6$ \\
\hline H3 & $82 \pm 11$ & H9 & $76 \pm 14$ & H15 & $89 \pm 8$ & H21 & $90 \pm 6$ \\
\hline H4 & $75 \pm 6$ & H10 & $85 \pm 12$ & H16 & $85 \pm 8$ & & \\
\hline $\mathrm{H5}^{*}$ & $67 \pm 14$ & H11 & $77 \pm 7$ & H17 & $84 \pm 16$ & & \\
\hline H6 & $75 \pm 14$ & $\mathrm{H} 12$ & $85 \pm 7$ & H18* & $89 \pm 11$ & & \\
\hline
\end{tabular}

*Significant difference between H5 and H18 only.

Table 3. Mean scores of ACC questions and its domains with respect to the type of the hospital and the number of hospital beds.

\begin{tabular}{|c|c|c|c|c|c|c|c|c|}
\hline & & Number & ACC & Registration & Continuous care & Discharge, referral and follow-up & Transfer & Transportation \\
\hline \multirow{3}{*}{$\begin{array}{l}\text { Type of the } \\
\text { hospital }\end{array}$} & General & 70 & 81.9 & 77.9 & 82.8 & 84.8 & 85.5 & 80.7 \\
\hline & Specialty & 84 & 82.6 & 79.3 & 82.9 & 85.6 & 84.5 & 82.5 \\
\hline & \multicolumn{2}{|c|}{ Pvalue } & 0.7 & 0.5 & 0.9 & 0.6 & 0.6 & 0.4 \\
\hline \multirow{3}{*}{$\begin{array}{c}\text { Number } \\
\text { of beds }\end{array}$} & $\leq 300$ & 80 & 82 & 78.5 & 82 & 85 & 84.9 & 81.3 \\
\hline & $>\mathbf{3 0 0}$ & 74 & 82.6 & 78.9 & 82.8 & 85.6 & 82 & 85.1 \\
\hline & \multicolumn{2}{|c|}{ Pvalue } & 0.7 & 0.8 & 0.4 & 0.76 & 0.9 & 0.7 \\
\hline
\end{tabular}




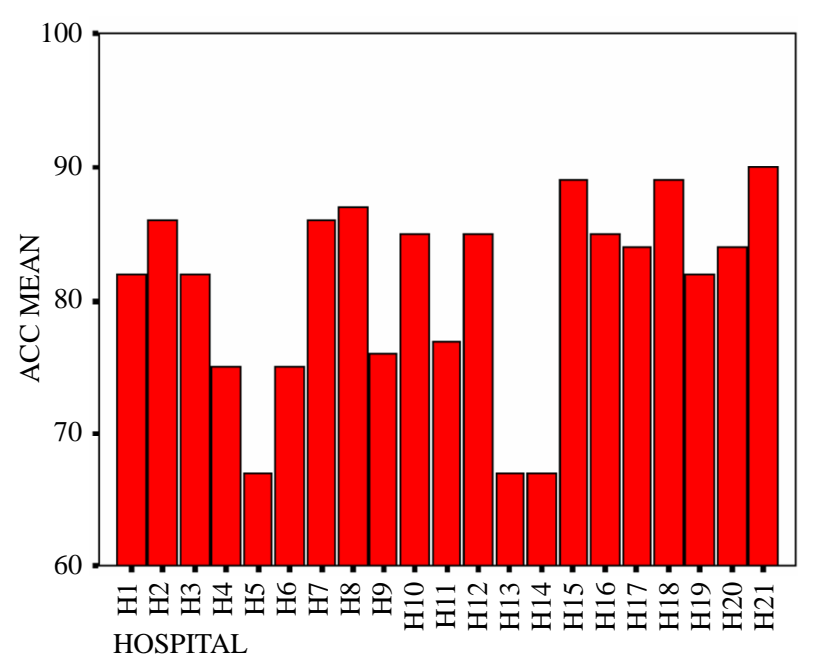

Figure 1. Comparing mean scores of ACC questions between the studied hospitals.

standards together, low familiarity with accreditation standards, low utilization of staff's experiences.

Risks: not supporting long-term cultural and organizational measures for care quality improvement, not having a single national standard for accreditation in the country.

\section{DISCUSSION}

\subsection{Applicability of the Standards}

Farzianpour et al. (2011) reported the applicability of JCI standards in quality improvement and patient safety (QPS) nearly 51.6\% with no significant difference between general and specialty hospitals $(\mathrm{P}$ value $=0.7)$; however the number of beds in the hospital was an effective factor on the applicability score of the standards ( $\mathrm{P}$ value $=0.03$ ) [16]. The applicability score in the present study was $82.2 \%$ for ACC standards, and also we didn't find any significant difference between general and specialty hospitals either $(P$ value $=0.7)$ and the number of beds showed no effect on the achieved scores $(\mathrm{P}$ value $=$ 0.7). These results indicate that the possibility of ACC standards improvement in the studied hospitals is much higher than QPS standards. The consistency between the two studies regarding ineffectiveness of the type of the hospital on the scores reflects the stability of the JCI questions in general or specialty hospitals; however this stability is affected by the number of the hospital beds which shows the necessity for further investigations.

\subsection{Scores of the Domains}

Hospitals admission domain: had the lowest applicability rate (78.6\%). Inappropriate or non-indicated admission is a common problem that requires proper investigation and different studies have reported various sta- tistics for it. Several factors have been suggested as possible causes including delay in diagnosis and operation processes, non-indicated hospitalizations before and after patient discharge, patients' characteristics such as age older than 60 years, no facilities for home care [17], educational level of the reception personnel and required facilities and tools [18]. Therefore it is necessary to explore the factors related to both the patient and the health care provider organizations. Preparation of specific guidelines for the patient admission unit, recruitment of skilled and interested staff, holding retraining courses, optimum resource allocation, providing the required equipment and environment, continuous evaluation of this unit and implementation of measures to improve the process for better function are among the important issues to consider for improvement of this domain [18].

Discharge, referral and follow-up domain: this domain showed the highest applicability evaluation (85.3\%). While Abbasi et al. (2012) in their investigation of availability of care and continuous treatment in Isfahan hospitals found that the lowest readiness in this domain and the mean readiness in the studied hospitals was estimated $75 \%$ in this domain [15].

\subsection{Hospitals' Accreditation}

Given that the respondents were asked to score the standards according to the hospital they were currently working at, it can be concluded that the score of the ACC questions for different hospitals is indeed the score of the hospital in the ACC standard domain. Accreditation of hospitals affiliated to Tehran University of Medical Sciences has been studied in several researches. Khodayari et al. (2010) reported ACC scores of 74\%, 63\% and 62\% in three specialty hospitals of Hasheminejad, Shahid Rajayi and Shahid Motahari (mean 66.3\%) and evaluated the situation of these hospitals as desirable in this domain [13]. These hospitals were not included in the present study, but the mean score for specialty hospitals was found $82.6 \%$. As can be observed, the values are not consistent and there is a nearly $16 \%$ difference.

Rahimi et al. (2012) found that mean score of CCUs and cardiology departments of specialty hospitals in Karaj was $67.5 \%$ in patient care standards of JCI. This value was $82.6 \%$ in our study [19]. In addition, Farzianpour et al. (2010) studied emergency departments of teaching hospitals affiliated to Tehran University of Medical Sciences using health ministry standard questionnaire ( 9 sets) and JCI based questionnaire and reported a mean score of $86.8 \%$ [20]. In our study the mean score in the ACC domain of JCI standards was $82.2 \%$ in all departments of the studied hospitals. Using health ministry standards together with JCI standards might be a reason for higher reported score in Farzianpour's study. Consistently, Ahmadi et al. (2010) compared JCI ACC stan- 
dards with hospitals evaluation standards of health ministry and reported $40 \%$ total consistency, $28 \%$ partial consistency and 32\% no consistency [18]. They concluded that whether the questions measuring the standards of health ministry are not designed appropriately or the questions are repeated in the questionnaire and generally speaking, it seems that the ministry has not paid enough attention to the continuous patient care area in preparation of the standards [18].

Abbasi et al. (2012) studied the adherence to 21 ACC standards in two hospitals affiliated to Social Security (with quality management system of ISO 9001-2008 certification) and one university hospital and reported standard scores of $71.1 \%, 73.4 \%, 75.6 \%$ and $74 \%$ (mean $73.5 \%$ ), respectively [15]. In this study, we checked 108 measurable components of ACC standards and found a mean score of $82.2 \%$ which is not consistent with Abbasi's findings and there is approximately $9 \%$ difference. Comparing the results of accreditation studies in different hospitals and departments indicates generally lower scores than the present study. It might be partly due to the type of the questions in our study which asked the respondents to evaluate the applicability of the standards. Therefore the $9 \%$ to $15 \%$ difference found in the scores reflects the possibility of improvement from the respondents' point of view which can be achieved through some modifications. A basic requirement for achieving JCI accreditation is having a comprehensive program for staff education and correcting some of the suggested improvement processes [14]. These measures can be more achievable by relying on strength points, using the opportunities and reducing the mentioned weak points and risks.

\subsection{Limitations}

Our research was a new subject, with limited resources access to Care and Continuity of Care for patients (ACC) considering the lack of research in this area. Other limitations were accreditation standards of patient that hospitals administrators and medical staff were less familiar with the accreditation standards of care of patients. So data Collection lasted because administrative problems in hospitals more than 3 months. Our study results are generated from public hospitals, which are located in Tehran. Therefore, the generalization of the results to the other public hospitals in Iran should be done cautiously, even though around $50 \%$ of these hospitals are operating in Tehran. Similar studies in other parts of the country might improve the generalizability of this study. In addition, other cross-sectional the studies are beneficial to monitor the ACC standards in private hospitals in Iran.

\subsection{Conclusion}

Our results demonstrate that the highest and lowest scores belonged to "discharge, referral and follow-up domain” and "admission domain”. ACC standards were considered comprehendible and measurable by the respondents. No significant difference was found between general and specialty hospitals regarding ACC standards and its domains. Although there was a 9\% - 15\% possibility of improvement in accreditation scores of ACC standards in hospitals of Tehran University of Medical Sciences, a complete accreditation score in this domain didn't seem achievable in these hospitals. However, it is proposed that future managerial planning of the studied hospitals lead to a complete accreditation score.

\subsection{Ethical Considerations}

Ethical issues (Including plagiarism, Informed Consent, misconduct, data fabrication and/or falsification, double publication and/or submission, redundancy, etc.) have been completely observed by the authors.

\section{ACKNOWLEDGEMENTS}

This research is based on post graduate doctoral proposal of Mr. S. Gary in health care management. We wish to thank the Research Department of Tehran University of Medical Sciences for financial support. We appreciate the kind collaboration of all the authorities in the studied teaching hospitals of Tehran University of Medical Sciences for careful completion of our questionnaires.

\section{REFERENCES}

[1] JCAH, Hospital Accreditation Standards (2012) Standards, elements of performance, scoring, accreditation policies. Joint Commission, One Renaissance Boulevard, Oakbrook Terrace.

[2] Emami Razavi, H. and Mohaghegh, M. (2008) Hospital accreditation standards. Seda Publication, Tehran.

[3] Topic Library Item (2013) Facts about the joint commission.

http://www.jointcommission.org/facts_about_the_joint_c ommission

[4] ARIAH, Improving America's Hospitals (2011) The joint commission's annual report on quality and safety. http://www.jointcommission.org/annualreport.aspx

[5] La Monica Rigolosi, E. (2012) Management and leadership in nursing and health care. 3rd Edition, Spring Publishing Company, New York, 56-67.

[6] Coughlin, T.A., Long, S.K., Sheen, E. and Tolbert, J. (2012) How five leading safety-net hospitals are preparing for the challenges and opportunities of health care reform. Health Affairs, 31, 1690-1697. http://dx.doi.org/10.1377/hlthaff.2012.0258

[7] Cunningham, P., Felland, L. and Stark, L. (2012) Safetynet providers in some us communities have increasingly embraced coordinated care models. Health Affairs, 31, 1698-1707. http://dx.doi.org/10.1377/hlthaff.2011.1270

[8] Schoenfelder, T., Klewer, J. and Kugler, J. (2010) Factors 
associated with patient satisfaction in surgery: The role of patients' perceptions of received care, visit characteristics and demographic variables. Journal of Surgical Research, 164, 53-59.

http://dx.doi.org/10.1016/j.jss.2010.08.001

[9] Mpinga, E.K. and Chastonay, P. (2011) Satisfaction of patients. A right to health indicator? Health Policy, 100, 144-150. http://dx.doi.org/10.1016/j.healthpol.2010.11.001

[10] Hekkert, K.D., Cihangir, S., Kleefstra, S.M., Bergand B.V.D. and Kool, R.B. ( 2009) Patient satisfaction revisited: A multilevel approach. Social Science \& Medicine, 69, 68-75.

http://dx.doi.org/10.1016/j.socscimed.2009.04.016

[11] Carpenter, K.B., Duevel, M.A., Lee, P.W., Wu, A.W. and Bates, D.W., et al. (2010) Measures of patient safety in developing and emerging countries: A review of the literature. Quality and Safety in Health Care, 19, 48-54. http://dx.doi.org/10.1136/qshc.2008.031088

[12] McCallum, B.T. and Jacoby, P.F. (2007) Medical outsourcing: Reducing client's health care risks. Journal of Financial Planning, 28, 415-437 www.ifebp.org/inforequest/0155471.pdf

[13] Khodayari Zrnqy, R., Turanian, S., Ghaderi, A., Salehi, M. and Jafari, H. (2001) Assess the capabilities of the selected educational hospitals of Tehran University of Medical Sciences in attracting medical tourists by standards of patient-centered of joint commission international. Journal of Hospital, 9, 51-56.

[14] Turani, S. (2000) Readiness of teaching hospitals - Iran University of Medical Sciences, to obtain a certificate of accreditation of the Joint Commission International (JCI): A patient-centered approach. Accreditation Conference Hospitals Designated by the Human Resources Empow- erment Foundation, Tehran, 126-132.

[15] Abbasi, S., Tavakoli, N. and Moslehi, M. (2012) Readiness of hospitals with quality management systems based on joint commission on accreditation standards. Health Information Management, 9, 1-11.

[16] Farzianpour, F., Arab, M., Amoozagar, S., Fouroshani, A.R. and Rashidian, A., et al. (2011) Evaluation of international standards of quality improvement and patient safety (QPS) in Hospitals of Tehran University of Medical Sciences (TUMS) from the managers' point of view. World Applied Sciences Journal, 15, 647-653.

[17] Ghahramani, F., Shaban Yamchi, T. and Shajarat, M. (2011) A comparison between standard requirements of admission units in Educational Hospitals of Shiraz and Ahvaz Universities of Medical Sciences. Health Information Management, 8, 439.

[18] Ahmadi, M., Khoshgam, M. and Mohamed, A. (2007) Ali. Comparative study of $\mathrm{MOH}$ standards with international standards of the joint commission on accreditation of healthcare. Hakim, I, 52-45.

[19] Rahimi, F., Mazraea Khatire, M., Farajollahi, F., Abbaspoor, M. and Sabet Deilami, T. (2012) Assessment of standard care (cop: care of patient) accreditation standards and clinical governance at the heart ccu1 Shahid Rajai Hospital in Karaj in 2012. 2nd National Conference on Patient Safety, Uremia, 3-5 October 2012, 34.

[20] Farzianpour, F., Askari, R., Torabipoor Hamedani, A., Khorshidi, G., Amirifar, S. and Hosseini, S. (2011) Accreditation of emergency department at a teaching hospital in Tehran University of Medical Sciences in 2010. American Journal of Economics and Business Administration, 3, 498-505. http://dx.doi.org/10.3844/ajebasp.2011.498.505

\section{ABBREVIATIONS}

ACC: Access to Care and Continuity;

JCI: Joint Commission International;

SWOTs: Strength, Weak, Opportunities, Treats;

SD: Standard Deviation;

QPS: Quality Patient Safety. 